\title{
A Comparison of Antinociceptive Activity of Mycelial Extract from Three Species of Fungi of Basidiomycetes
}

\author{
Chunchao Han* \\ School of Pharmacy, Shandong University of Traditional Chinese Medicine, Jinan 250355, P.R China
}

\begin{abstract}
The antinociceptive activity of mycelial extract from fermented mushroom of Ganoderma lucidum, Coprinus comatus and Grifola frondosa were studied in this paper. The writhing test, formalin test and hot-plate test were used to evaluate the antinociceptive activity of the acetone extracts of the three Species of Fungi of Basidiomycetes in the study respectively. The extract of Ganoderma lucidum inhibited in a dose-dependent manner the acetic acid-induced abdominal constrictions in mice $(p<0.05)$. Also both phases of the response were significantly inhibited in the formalin test $(p<0.05)$. In the hot-plate test, results showed that extract of Ganoderma lucidum significantly inhibited the reaction time to thermal stimuli at 30,60, and $90 \mathrm{~min}(p<0.05)$. The preliminary toxicologic study demonstrated the safety of it. However the extract from fermented mushroom of Coprinus comatus and Grifola frondosa did not show significantly expectative antinociceptive effect. Our results show the acetone extract of Ganoderma lucidum is a potent analgesic drug.
\end{abstract}

Key Words: Antinociceptive activity, Ganoderma lucidum, Coprinus comatus, Grifola frondosa.

\section{INTRODUCTION}

Various edible mushrooms have a long history of use in traditional Chinese medicine [1]. Some further mushroom extracts and compounds have been found with special central effects that could be of pharmacological interest. Marc Stadler [2] reported that acetone extract from several edible mushrooms of basidiomycetes, showed strong activities against neurolysin, a protease involved in the regulation of dynorphin and neurotensin metabolism. There have been report that the anti-inflammatory and antinociceptive properties of the methanol extract of I. obliquus may be due to the inhibition of inducible nitric oxide (NO) synthase (iNOS) and cyclooxygenase-2 (COX-2) expression via the downregulation of nuclear factor kappaB (NF-kappaB) binding activity [3]. The n-BuOH subfraction of Phellinus linteus also showed highest inhibitory activity on the chick embryo chorioallantoic membrane (CAM) angiogenesis in a dosedependent manner. The results suggest that Phellinus linteus has anti-inflammatory and antinociceptive activities, in addition to its anti-angiogenic activity [4]. Ganoderma lucidum, Coprinus comatus and Grifola frondosa are three Fungi of Basidiomycetes that have a long history of use in traditional Chinese medicine. An earlier study [5] performed with the $\mathrm{CH} 2 \mathrm{Cl} 2$ extract of Ganoderma lucidum demonstrated that these extracts possess antinociceptive activity. But there were no reports about the acetone extract of Ganoderma lucidum, Coprinus comatus and Grifola frondosa on antinociceptive activity. The objectives of the present study were to compare the antinociceptive activity of mycelial extract from the three Species of Fungi of Basidiomycetes.

\footnotetext{
*Address correspondence to this author at the School of Pharmacy, Shandong University of Traditional Chinese Medicine, Jinan 250355, P.R China; E-mail: sdscipaper@126.com
}

\section{MATERIALS AND METHODS}

\subsection{General}

If not indicated otherwise, all chemicals were provided by Sigma Aldrich (Deisenhofen, Germany), while media ingredients was purchased from Tianjin

Xing Yu Chemical Co.,Ltd, China. Yuanhuzhitong capsules (YHZT) were purchased from Jinan Limeng Pharmaceutic Factory, China. Yuanhuzhitong capsule is a kind of Chinese medicine used in the treatment of pain. It is composed of two traditional Chinese herbs, including RhizomaCorydalisYanhusuo and Radixngelicae Dahuricae.

\subsection{Fermented Mushroom of Ganoderma lucidum, Co- prinus comatus and Grifola frondosa}

Fermented mushroom of Ganoderma lucidum , Coprinus comatus and Grifola frondosa were produced in the Pharmaceutic Laboratory of Shandong University of Traditional Chinese Medicine, China.

The seed of Ganoderma lucidum, Coprinus comatus and Grifola frondosa was purchased from the Agricultural Culture Collection of China.

First, the seed was grown at $28^{\circ} \mathrm{C}$ for 5 days on PDA slants $(1,000 \mathrm{~mL} 20 \%$ potato extract liquid $+20.0 \mathrm{~g}$ dextrose $+20.0 \mathrm{~g}$ agar) and then maintained at $4^{\circ} \mathrm{C}$ in a refrigerator. Five to six pieces of the mycelia of the mushrooms were transferred from a slant into $250 \mathrm{~mL}$ Erlenmeyer flasks containing $100 \mathrm{~mL}$ liquid medium $(20 \%$ potato extract liquid $+2.0 \%$ dextrose $+0.1 \% \quad \mathrm{KH}_{2} \mathrm{PO}_{4}+0.05 \% \quad \mathrm{MgSO}_{2}$ ). The culture was incubated at $27^{\circ} \mathrm{C}$ on a rotary shaker at $180 \mathrm{rmp}$ for 3 days.

A 72-h-old liquid culture was homogenized using a sterilized blender and then inoculated to $500 \mathrm{~mL}$ Erlenmeyer 
flasks containing $300 \mathrm{~mL}$ of fermented culture medium $(20 \%$ potato extract liquid $+2.0 \%$ dextrose $+0.1 \% \mathrm{KH}_{2} \mathrm{PO}_{4}+0.05 \%$ $\mathrm{MgSO}_{2}$ ). The volume of inoculum was $15 \mathrm{~mL}$, which was then cultivated under the same condition. The 72-h-old fermented liquid culture was the fermented mushroom.

\subsection{Extracts from Fermented Mushroom of Ganoderma lucidum (EGL), Coprinus comatus (ECC)and Grifola frondosa(EGF)}

Mycelia were separated from the culture fluid by filtration and extracted twice with acetone for 30 minutes in an ultrasonic bath. The extract was filtered, and the acetone was removed in vacuo $\left(\mathrm{ca} .40^{\circ} \mathrm{C}, 250 \mathrm{mbar}\right)$ to yield an aqueous residue. Then it was dried to powers.

\subsection{Animal}

Kunming strain mice weighing 20-22g, were purchased from the Experimental Animal Center, Shandong University. The mice were maintained at room temperature under alternating natural light/dark photoperiod, and had access to standard laboratory food and fresh water ad libitum.

\subsection{Evaluation of Antinociceptive Activity}

\subsubsection{Writhing Test}

This test is used for the evaluation of analgesic activity. Mice were treated with EGL, ECC and EGF respectively (1, 5 , and $10 \mathrm{mg} / \mathrm{kg}$, orally), $60 \mathrm{~min}$ before receiving a $0.6 \%$ acetic acid injection $(10 \mathrm{~mL} / \mathrm{kg}$, ip $)$. The number of contractions or writhings, determined by abdominal muscle contractions and hind paw extension was recorded for $20 \mathrm{~min}$, starting $10 \mathrm{~min}$ after the administration of acetic acid [6]. YHZT $(5 \mathrm{mg} / \mathrm{kg}, \mathrm{po})$ was used as standard.

\subsubsection{Formalin Test}

This test, which causes a local tissue injury to the paw, has been used as a model for tonic pain and localized inflammatory pain. For this, $20 \mu \mathrm{L}$ of a $1 \%$-formalin solution was injected into the right hind paw of mice, and the licking time was recorded after the first $5 \mathrm{~min}$ (1st phase, corresponding to a direct chemical stimulation of nociceptors) and after $20 \mathrm{~min}$ (2nd phase, involving inflammation), for $5 \mathrm{~min}$ each time. Animals were pretreated respectively with EGL, ECC and EGF 60 min (po) before intraplantar formalin injection $[7,8]$. YHZT was used as standard.

\subsubsection{Hot-Plate Test}

In this test, mice were pre-selected according to their reactions to a thermal stimulus (jumping or licking of hind limbs when placed on a hot plate at $55^{\circ} \mathrm{C}$ ). Latency times were recorded immediately before and 30, 60 and 90min after drug administration, up to a maximum time of $40 \mathrm{~s}$ to avoid paw lesions [9].

\subsubsection{Acute Toxicity}

The acute toxicity of EGL was investigated using a single oral administration of EGL in mice. In this assay, increasing doses of the test substance were orally administered to animals (up to $150 \mathrm{mg} / \mathrm{kg}$ ). The animals were observed for 14 days and at the end of this period the number of survivors was counted and body and spleen weight was recorded.

\subsection{Statistical Analysis}

All data were analyzed by a one-way analysis of variance, and the differences between means were established by Duncan's multiple-range test [10]. The data represents means and standard deviations. The significant level of 5\% $(p<0.05)$ was used as the minimum acceptable probability for the difference between the means.

\section{RESULTS}

In the writhing test, EGL $(1,5$, and $10 \mathrm{mg} / \mathrm{kg})$ inhibited in a dose-dependent manner the acetic acid-induced abdominal constrictions in mice after po $(41,61$, and $83 \%)$ administration (Table 1). As well as EGL, YHZT also inhibited the acetic acid-induced abdominal constrictions in mice. However, ECC and EGF, given orally $60 \mathrm{~min}$ before receiving a $0.6 \%$ acetic acid injection did not significantly inhibited the acetic acid-induced abdominal constrictions in mice.

In the formalin test (Table 2), although both phases of the response were significantly inhibited, the EGL effect was predominant in phase 2, causing 61 and $48 \%$ inhibition of licking time at the doses of 5 and $10 \mathrm{mg} / \mathrm{kg}$, po, similarly to YHZT. In this test, neither in phase 1 nor in phase 2, did ECC and EGF inhibit significantly the response caused by formalin.

The hot-plate test was performed for the assessment of the central antinociceptive effect of extracts (Table 3). Results showed that EGL significantly inhibited the reaction time to thermal stimuli at 30,60 , and $90 \mathrm{~min}$ after $p o$ administration of 1,5 , and $10 \mathrm{mg} / \mathrm{kg}$ compared to controls. So is the YHZT. However, ECC and EGF did not show significantly antinociceptive effect.

In preliminary toxicologic study, deaths were not observed even at the level of $150 \mathrm{mg} / \mathrm{kg}$. In addition, EGL did not cause significant changes in body or spleen weight of the animals, demonstrating the safety of EGL (Table 4).

\section{DISCUSSION}

The acetic acid-induced writhing reaction in mice, described as a typical model for inflammatory pain, has long been used as a screening tool for the assessment of analgesic or anti-inflammatory properties of new agents [11]. The constrictions induced by acetic acid in mice result from an acute inflammatory reaction related to the increase in the peritoneal fluid levels of $\mathrm{PGE}_{2}$ and $\mathrm{PGF}_{2} \alpha$ [12]. The fact that EGL was able to inhibit constrictions showed that this fraction has a peripheral antinociceptive effect.

The formalin test is different from most models of pain. It is possible to assess the way an animal responds to moderate, continuous pain generated by injured tissue. This model is constituted by two distinct phases. The first phase represents the irritating effects of formalin at the sensorial fibers$\mathrm{C}$ [13]. The second is an inflammatory pain response. Thus, it's possible to appraise the animal's answer to a moderate and continuous pain caused by the tissue lesion as well as the role of pain regulatory endogenous systems. The formalin test indicated that both peripheral analgesic properties and central analgesic effects are the antinociception mechanism of EGL. To corroborate that EGL also had central analgesic actions, hot plate test were conducted. 
Table 1. Inhibitory Effect of Extracts in Mice Submitted to the Writhing test $(\mathrm{N}=10)$

\begin{tabular}{|c|c|c|}
\hline \multicolumn{3}{|l|}{ Distilled water $1 \mathrm{~mL} / \mathrm{kg}$, po } \\
\hline EGL $1 \mathrm{mg} / \mathrm{kg}, p o$ & $13.9 \pm 1.8$ & $41 \% *$ \\
\hline EGL $10 \mathrm{mg} / \mathrm{kg}$, po & $4.1 \pm 1.7$ & $83 \% *$ \\
\hline $\mathrm{ECC} 1 \mathrm{mg} / \mathrm{kg}$, po & $19.0 \pm 1.6$ & $19 \%$ \\
\hline ECC $5 \mathrm{mg} / \mathrm{kg}$, po & $18.6 \pm 1.4$ & $21 \%$ \\
\hline $\mathrm{EGF} 10 \mathrm{mg} / \mathrm{kg}, p o$ & $17.1 \pm 1.5$ & $27 \%$ \\
\hline YHZT $5 \mathrm{mg} / \mathrm{kg}$, po & $3.9 \pm 1.7$ & $83 \% *$ \\
\hline
\end{tabular}

The asterisks in the last column indicate a statistical difference $(p<0.05)$.

Table 2. Antinociceptive Effect of Extracts in Mice Submitted to the Formalin Test $(\mathbf{N}=10)$

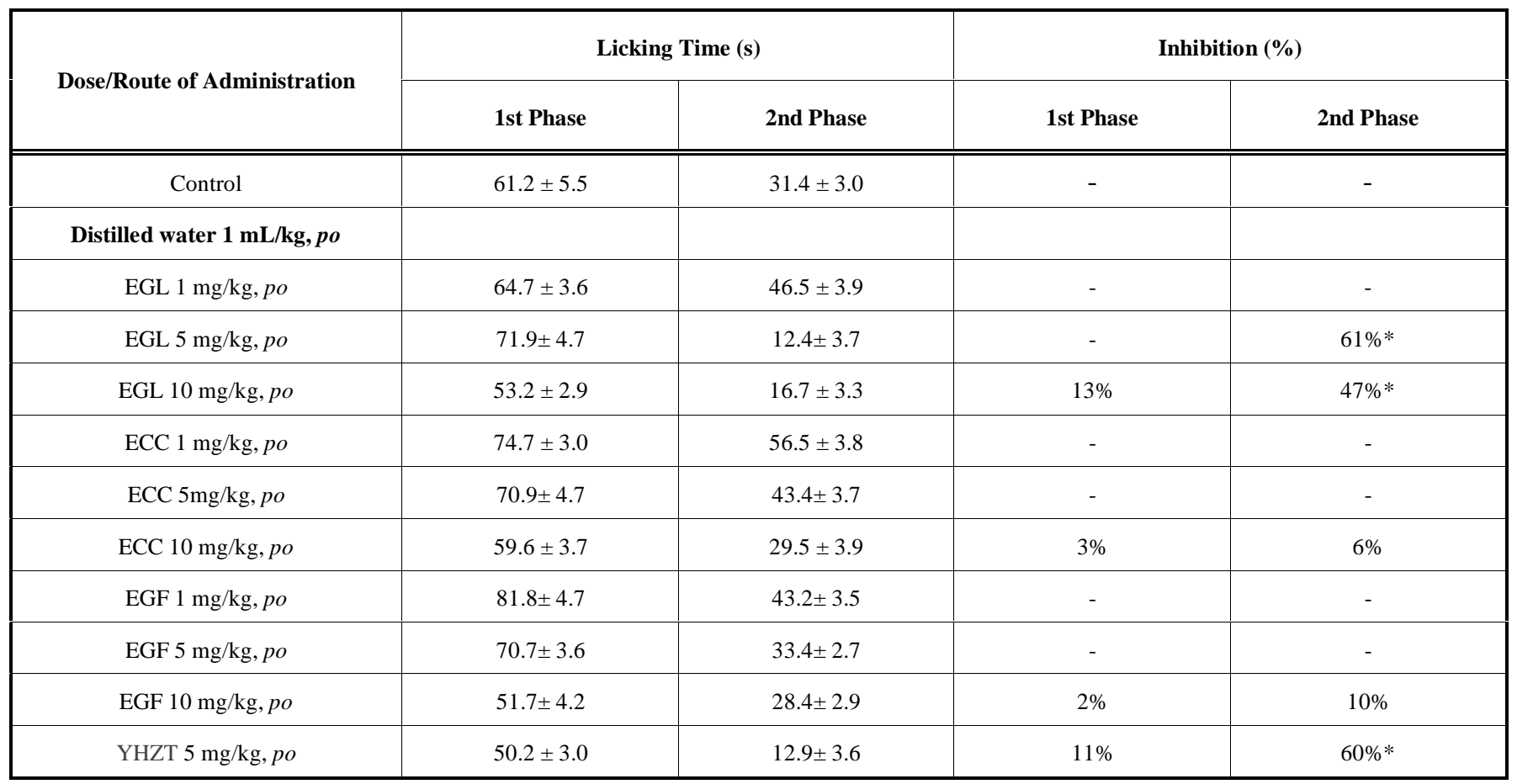

The asterisks in the last column indicate a statistical difference $(p<0.05)$.

The hot-plate test is commonly used to assess narcotic analgesics or other centrally acting drugs [14]. The hot-plate test was performed for the assessment of the central antinociceptive effect of EGL. Results showed that EGL also had central analgesic actions.
Although Marc Stadler [2] reported that acetone extract from several edible mushrooms of basidiomycetes, showed antinociceptive effect, the acetone extract from Coprinus comatus and Grifola frondosa did not show the expectative antinociceptive effect. 
Table 3. Effect of Extracts in Mice Submitted to the Hot-Plate Test $(\mathrm{N}=10)$

\begin{tabular}{|c|c|c|c|c|}
\hline Dose/Route of Administration & $0 \mathrm{~min}$ & $30 \mathrm{~min}$ & $60 \mathrm{~min}$ & $90 \mathrm{~min}$ \\
\hline Control & $11.8 \pm 0.8$ & $10.6 \pm 0.9$ & $8.3 \pm 0.80$ & $9.5 \pm 0.6$ \\
\hline \multicolumn{5}{|l|}{ Distilled water $1 \mathrm{~mL} / \mathrm{kg}$, po } \\
\hline EGL $5 \mathrm{mg} / \mathrm{kg}$, po & $7.9 \pm 0.9$ & $10.5 \pm 1.1$ & $16.4 \pm 0.8 *$ & $15.8 \pm 1.2 *$ \\
\hline EGL $10 \mathrm{mg} / \mathrm{kg}$, po & $10.9 \pm 1.2$ & $14.3 \pm 0.8 *$ & $15.8 \pm 1.1 *$ & $16.4 \pm 1.1^{*}$ \\
\hline $\mathrm{ECC} 1 \mathrm{mg} / \mathrm{kg}$, po & $9.9 \pm 1.0$ & $9.2 \pm 1.9$ & $9.6 \pm 1.8$ & $8.5 \pm 0.9$ \\
\hline EGF $5 \mathrm{mg} / \mathrm{kg}, p o$ & $9.9 \pm 2.0$ & $8.7 \pm 0.7$ & $10.8 \pm 1.5$ & $10.7 \pm 0.9$ \\
\hline EGF $10 \mathrm{mg} / \mathrm{kg}$, po & $10.8 \pm 0.8$ & $10.2 \pm 1.5$ & $11.4 \pm 2.7$ & $9.9 \pm 012$ \\
\hline YHZT $5 \mathrm{mg} / \mathrm{kg}$, po & $9.9 \pm 1.0$ & $13.5 \pm 1.1^{*}$ & $16.4 \pm 0.8^{*}$ & $16.4 \pm 1.1^{*}$ \\
\hline
\end{tabular}

The asterisks in the last column indicate a statistical difference $(p<0.05)$.

\section{CONCLUSION}

In the present study, we report a comparison of antinociceptive activity of mycelial extract from three Species of Fungi of Basidiomycetes, Ganoderma lucidum, Coprinus comatus and Grifola frondosa. Our results show that EGL is a potent analgesic drug. However the ECC and EGF did not show significantly expectative antinociceptive effect. Although Marc Stadler [2] reported that acetone extract from several edible mushrooms of basidiomycetes, showed antinociceptive effect, not all the acetone extract from edible mushrooms of basidiomycete show analgesic actions.

Table 4. The Acute Toxicity Trial of EFMG on Mice $(\mathrm{N}=12)$

\begin{tabular}{|c|c|c|}
\hline & 0d & 14d \\
\hline \hline Deaths & - & 0 \\
\hline Body weight $(\mathrm{g})$ & $21.2 \pm 1.0$ & $23.0 \pm 1.3$ \\
\hline Spleen weight $(\mathrm{mg} / \mathrm{g})$ & $4.2 \pm 1.6$ & $4.4 \pm 1.0$ \\
\hline
\end{tabular}

No significant changes in body or spleen weight were observed at the dose level of $150 \mathrm{mg} / \mathrm{kg}$.

As an edible mushroom of basidiomycetes, acetone extract of Ganoderma lucidum, showed potent antinociceptive activity. The preliminary toxicologic study demonstrated the safety of EGL. It supports the folk medicinal use of this mushroom. Further studies currently in progress will enable us to understand the mechanisms of action underlying the effects observed in this investigation. And there is a need for further studies on the identification and isolation of biologically active natural products from Ganoderma lucidum.

\section{REFERENCES}

[1] Demirbas A. Heavy metal bioaccumulation by mushrooms from artificially fortified soils. Food Chem 2001; 74: 293-1.

[2] Stadler M, Hellwig V. Novel analgesic triglycerides from cultures of Agaricus macrosporus and other basidiomycetes as selective inhibitors of neurolysin. J Antibiot 2005; 58: 775-6.

[3] Kim HG, Yoon DH, Kim CH. Ethanol extract of inonotus obliquus inhibits lipopolysaccharide-induced inflammation in RAW 264.7 macrophage cells. J Med Food 2007; 10: 80-9.

[4] Kim SH, Song YS, Kim SK. Anti-inflammatory and related pharmacological activities of the $\mathrm{n}-\mathrm{BuOH}$ subfraction of mushroom Phellinus linteus. J Ethnopharmacol 2004; 93: 141-6.

[5] Koyama K, Imaizumi T, Akiba M. Antinociceptive components of Ganoderma lucidum. Planta Med 1997; 63: 224-7.

[6] Koster R, Anderson M, DeBeer EJ. Acetic acid for analgesic screening. Fed Proc 1959; 18: 418-20.

[7] Fasmer OB, Berge OG, Hole K. Changes in nociception after lesions of descending serotonergic pathways induced with 5,6 dihydroxytryptamine. Different effects in the formalin and tail-flick tests. Neuropharmacology 1985; 24: 729-34.

[8] Hunskaar S, Hole K. The formalin test in mice: dissociation between inflammatory and non-inflammatory pain. Pain 1987; 30: 103-14.

[9] Woolfe G, MacDonald AD. The evaluation of the analgesic action of pethidine hydrochloride (demerol). J Pharmacol Exp Ther 1944; 80: $300-7$.

[10] Duncan DB. Multiple range tests for correlated and heteroscedastic means. Biometrics 1957; 13: 164-76.

[11] Collier HOJ, Dinneen JC, Johnson CA, Schneider C. The abdominal constriction response and its suppression by analgesic drugs in the mouse. Br J Pharmacol Chemother 1968; 32: 295-10.

[12] Deraedt R, Jouquey S, Delevalée F et al. Release of prostaglandins$\mathrm{E}$ and prostaglandins- $\mathrm{F}$ in an algogenic reaction and its inhibition. Eur J Pharmacol 1980; 61: 17-24. 
[13] Hosseinzadeh H, Ramezani M, Salmani GA. Antinociceptive, antiinflammatory and acute toxicity effect of Zataria multiflora Boiss extracts in mice and rats. J Ethnopharmacol 2000; 73: 379-85.
[14] Beirith A, Santos ARS, Rodrigues ALS, et al. Spinal and supraspinal antinociceptive action of dipyrone in formalin, capsaicin and glutamate tests. Study of the mechanism of action. Eur J Pharmacol 1998; 345: 233-45.

(c) Chunchao Han; Licensee Bentham Open.

This is an open access article licensed under the terms of the Creative Commons Attribution Non-Commercial License (http://creativecommons.org/licenses/ by-nc/3.0/) which permits unrestricted, non-commercial use, distribution and reproduction in any medium, provided the work is properly cited. 